\title{
Individualized Learning in Context: Constructivists' Teaching Philosophy of Academic Writing for EAL Learners
}

\author{
Yuehai Xiao ${ }^{1} \&$ Angel Zhao ${ }^{2}$ \\ ${ }^{1}$ Department of English, Hunan Normal University, China \\ ${ }^{2}$ English Language Centre, Beijing Normal University-Hong Kong Baptist University United International \\ College, China \\ Correspondence: Angel Zhao, English Language Centre, Beijing Normal University-Hong Kong Baptist \\ University United International College, China. E-mail: angelshzhao@uic.edu.hk
}

Received: July 21, $2020 \quad$ Accepted: August 28, $2020 \quad$ Online Published: September 7, 2020

doi:10.5539/ijel.v10n5p360 URL: https://doi.org/10.5539/ijel.v10n5p360

\begin{abstract}
The prominent role of teaching philosophy statements is on the rise because they mirror broad skillsets and the expertise of doctoral or master's program graduates (Merkel, 2020). This paper presents our philosophy of education, of Teaching English to Speakers of Other Languages (TESOL), and of teaching academic writing for English as an Additional Language (EAL) students. First, it is maintained that in education, knowledge is individually and socially constructed (Piaget, 1970; Vygotsky, 1981). In light of the constructivists' educational philosophy, it is argued that the EAL teachers need to possess knowledge in cognate disciplines to mediate the EAL students' construction of their individualized linguistic and intercultural knowledge in dynamic, specific learning contexts. Finally, innovative pedagogical suggestions for what to cover and how to deliver the second language (L2) academic writing class with EAL students are offered.
\end{abstract}

Keywords: EAL, constructivist, teaching philosophy, L2 academic writing

\section{Introduction}

The teaching philosophy statements usually underscore doctoral or master's program graduates' teaching commitment and their reflections upon their prior teaching experience, conceptualization of theoretical models for teaching and learning, effective pedagogy as well as closing the theory and practice gap through nursing praxis (Eierman, 2008, cited in Merkel, 2020). The EAL writing class is considered an indispensable component of Teaching English to Speakers of Other Languages (TESOL) practice and research (Xiao, Ma, \& Chen, 2020). In this paper, which is an expanded version of a teaching philosophy statement, we will present our teaching philosophy of EAL academic writing class, in relation to education in general and to the field of TESOL. We will begin the exposition with our view on education through a constructivist's lens. Then with the principles of education from such a perspective, we will scrutinize our philosophy of TESOL. Finally, based on these discussions, we will propose our philosophy of the EAL academic writing course. The underpinning of our teaching approach is that instructors need to foster individualized learning in specific educational contexts with the EAL students in an academic writing course.

\section{Our Philosophy of Education}

Informed by the literature and based on our reflections upon English language teaching (ELT), the authors of this paper are gradually shaping our philosophy of education, developing our philosophy of the field of TESOL, and forming our teaching philosophy of the course "Academic Writing for EAL Students." We perceive education as an ongoing process of constructing the learners' knowledge; we believe that the field of TESOL should underscore inter-cultural communication (Xiao, Zhao, \& Chen, 2020); and we think the EAL course of academic writing should aim to prepare the EAL students to join the academic discourse community.

To begin with, an individual's new knowledge is constructed based on his/her social environment and prior knowledge in a specific context (Piaget, 1970; Vygotsky, 1981). First, an individual's knowledge is socially constructed (Vygotsky, 1981). It refers to the fact that a piece of knowledge has to be accepted by the society before it becomes an individual's knowledge and that the individual has to learn this knowledge in the context of his/her society. For example, the Earth's shape was perceived as a flat plane before it was viewed as spherical in 
the 20th century. Therefore, individual learners would most likely see the Earth's shape as flat if that was the knowledge of the society at the time. Furthermore, some knowledge may vary with contexts. For example, the color white is regarded as pure and holy in some cultures, while it is associated with sorrow and used in funerals in other countries. On the other hand, knowledge is also individually constructed by the addition of new knowledge to the prior knowledge of the individual; thus it is an accumulative individual process (Wong \& Lim, 2014). In the previous example, the learner's prior knowledge may include how people dress in weddings and funerals before the learner can understand the different implications of colors.

The process of education is a process of knowledge construction (Olofson, Swallow, \& Neumann, 2016). As such, education needs to be viewed from a constructivist's perspective, and the following shall be included in it. 1) Education involves a combination of the student's motivation, conscious efforts, and self-education and the society's impacts, such as peer interaction, parental involvement, and community attention. 2) New knowledge is built based on the individual's previous knowledge and the consensus of the society. 3) Knowledge evolves. Therefore, individual learning is life-long and the goal of different scholars' research is to advance human knowledge. Both are ongoing processes in response to an ever-changing world. 4) Learning cannot be effective unless it is individualized and contextualized. "Individualized" means each learner has his/her own learning style, pace, and preference. Their previous knowledge and experience are unique. "Contextualized" refers to the fact that learning occurs in specific context, in which the specific time, place, people, institution, culture, and other factors are all intertwined. For instance, Fu, Lin, Hwang and Zhang (2019) advocate the use of a "mind mapping-based contextual gaming approach" to improving learners' English writing, and their study receives positive feedback from the learners (p. 59).

Education aims to achieve multiple goals, which include: the learners' familiarity of the subject, social adaptation, preparing an individual to join the work force, achieving personal potential, character development, spiritual growth, and maintaining consistency of value, morality, order, and harmony of the society (Ovortrup \& Wiberg, 2017). To these ends, a good educator should try to establish rapport and empathy with the students, encourage them regularly, promote the idea of life-long self-education, prepare the students for future employment, customizes education based on their needs, foster creativity and innovation, and teach the students important values of a culture. The role of a teacher varies with cultural and learning contexts. We believe that he/she can be an authority, a judge, a guide, a facilitator, a coach, and an advanced learner.

Furthermore, we believe preparation and passion make good teaching. That is to say, the art of teaching lies in meticulous preparation. 1) The teacher should familiarize himself/herself with the learning context, society, and culture. For example, the teacher may examine the expectations from the parents, the community, and the university regarding the learning outcome. 2) The instructor should know the students well. For instance, the teacher may need to learn about the students' academic and cultural background and level of the subject. The teacher may also conduct a needs analysis before class, and incorporate the feedback into his/her syllabus design and instruction (Douglas, 2017). 3) The instructor needs to prepare carefully for his/her lessons by going through the course materials such as textbook, handouts, PPT and audiovisual files to design teaching procedures and engaging activities before class.

The instructor's passion for teaching and his/her creativity may contribute to the success of the class. The authors are passionate about educating students and find the job of an educator rewarding. We are always happy to witness the students' academic, social, and emotional growth. For example, the first author walked into the classroom one day and some students were there already. Yet no one turned on the lights. So he waited until most of them arrived, then asked the students, would you like the lights to be turned on? Many of them said "NO. We want to do our presentations in the dark." He went along with it and did not turn on the light. The class started and the students began to deliver their presentations in the dark. About 5 minutes later, a few of them raised their hands and one of them said, "Can I turn on the lights?" He said. "of course. Thank you for turning on the lights", the first author replied. That was a simple, yet inspiring anecdote. The students learned to make independent decisions by themselves. They also learned to take actions on their decisions. What we learned was that it is important to sometimes let students make independent decisions and to allow them to bear the consequences of their decisions. This is crucial to their growth.

Learning is more important than teaching (Matukhin \& Bolgova, 2015). Because the ultimate purpose of teaching is to see the outcome of learning. The goal of teaching is to help the students construct knowledge instead of imparting knowledge to the students, which is essentially spoon-feeding. It is important for teachers to learn to build new knowledge based on students' prior knowledge. The goal of teaching ultimately comes back to students' learning outcome (Caskurlu, Maeda, Richardson, \& Lv, 2020). 


\section{Our Philosophy of TESOL}

In the same manner, most of the above underpinning principles of education, which derive from constructivism, may also be applicable to the field of TESOL. Educators in TESOL, however, may need to expose themselves to additional interdisciplinary knowledge so that they can assist the EAL students construct individual knowledge in specific learning contexts. For instance, the instructors need to possess:1) knowledge of English language, including high English proficiency and the history, present situation, and future development of English language teaching; 2) knowledge of teaching methods (e.g., grammar-translation, audio-lingual, communicative approaches, see Celce-Murcia, 2013 and Task-based language teaching, see Ellis, Skehan, Li, Shintani, \& Lambert, 2019), so that the instructors are qualified to teach English; 3) knowledge and experience of second language learning (which means that it may be helpful for ELT teachers to have experience learning a second language), so that they have effective strategies to offer their students and are able to relate to the EAL students' problems; 4) knowledge of educational psychology and cultural difference applicable to their specific contexts, so that they can handle the challenges in teaching students from a wide variety of academic and cultural backgrounds and customize their classes to address students' needs; 5) knowledge of immigrant history, so that empathy towards the EAL learners' struggles can be established and understanding of the immigrants' ambitions can be achieved; and 6) being aware of and respect diverse cultural values and beliefs. For example, some researchers, such as Ersin and Atay (2020), recommend pre-service teachers to take courses relating to intercultural sensitivity in their teacher training.

The communicative language teaching (CLT) method has two main guiding principles: language functions and opportunities to use language (Svignon, 2006). First, the supporters of communicative language teaching claim that successful language learning involves functions and purposes that a language serves in different communicative settings as well as knowledge of structure and forms of language. Thus, this approach emphasizes meaningful communication and interaction rather than drills and memorization of forms and rules. In addition, they argue that when students are exposed to English and have enough opportunities to use it, they will learn the language (Harmer, 2007). According to Hoyatt (2004), there are weak and strong versions of CLT. The first one is using English for communication purposes. In contrast, the latter is speaking English in order to learn it. As fluency is an important aspect of communication, students have time to participate in various activities such as interviews, role-plays and games with their peers.

When conducting various communicative activities such as role-plays and games, the instructor should provide a comfortable atmosphere because students might feel shy. He/she should not criticize the students' unsuccessful attempts and should treat them in a respectful and friendly manner. In addition, he/she ought to encourage them to speak by praising them when they do a good job.

For example, an instructor may motivate the students to learn English with praise and foster academic growth and emotional maturity. He/she may stimulate their interests in learning through well-designed activities, and train them with study skills, learning strategies and test taking strategies, so that they can become autonomous learners (Ceylan, 2015). By creating a positive and supportive environment that is conductive to learning, he/she will be able to challenge them intellectually and push their limits.

The instructor may also carry out some class activities such as a grammar game for his/her EAL students. It goes like this: Every student writes down a grammar topic and puts it in the topic bag. Then, a student draws a topic from the bag. Whichever grammar topic he/she draws, he/she will need to stand up and tell the class about it. If he/she does it well, the class will applause and then the instructor will say, "good work!", if he/she tries but does not do well, the class will still applause and the instructor will say "Nice try!"

\section{Our Philosophy of Teaching EAL Students Academic Writing}

From the above discussion, we can understand education and TESOL better from the constructivists' perspective, and place the academic writing course for the EAL students under the umbrellas of TESOL and education. Next, we will present our teaching philosophy of the EAL academic writing course, that is, to promote individualized learning in specific contexts, reflecting the assertion that individual knowledge is socially (Vygotsky, 1981) and individually (Piaget, 1970) constructed. "Individualized learning" corresponds to the claim that knowledge is "individually" constructed. And "specific contexts" are aligned with the argument that knowledge is "socially" constructed in contexts. "Individualized learning" refers to the attention to individual student's learning styles and needs, whereas "specific context" refers to the university's expectations of the learning outcome, the local culture and the students' academic community. Below we will offer some suggestions on what to cover and how to deliver the EAL academic writing class based on that teaching philosophy.

Academic writing is the way that scholars communicate with one another and also a crucial means for the professors to evaluate university students' academic performance (Hyland, 2016). In the case of university EAL 
students, it is essentially writing across cultures and curricula. The goal of an EAL academic writing course is to prepare university EAL students for the academic writing tasks in English as medium of instruction universities. Therefore, the EAL students need to construct their knowledge of academic writing individually and pick up the writing conventions in their own field, be it engineering, business, medicine, math, chemistry, or education... etc.

Instructors of an academic writing class with EAL students need to cover the concepts (e.g., audience and purpose), processes (e.g., prewriting, drafting, and revising, see Palermore \& Wilson, 2020), rhetorical patterns (e.g., five-paragraph essay, research paper, cause and effect, compare and contrast, exemplification and exposition), and conventions (e.g., citations and references) of academic writing. Specifically, the EAL students need to learn how to complete various academic writing tasks encompassing quoting, paraphrasing, summarizing, critique, literature review, annotated bibliography, book review, research proposal, and research report. The students may also need to learn rhetorical and content expectations of the English as medium of instruction (EMI) universities and of their own disciplines (Dimova, 2020). Other issues pertaining to academic writing comprise critical thinking skills; voice and identity; first language and second language relationships; reading and writing connections; the recursive writing process; peer review and assessment; and writing with technology (Polio, 2017 ).

How shall we teach academic writing to EAL students? We believe that we need to create a collaborative workshop-like class. The EAL students need to construct their knowledge of academic writing individually with hands-on experience in an unthreatening environment and in the specific learning contexts. In a collaborative writing workshop, the EAL students would be able to: 1) contribute to syllabus design (e.g., suggesting the texts and topics for the class); 2) write for a real audience such as the instructor and their peers; and 3) benefit from peer response and instructor's feedback. The writing course should focus on: 1) analyzing the context and purpose of each writing task; 2 ) reading-to-write (for the learners to learn the structure and vocabulary words for the writing tasks); 3) practicing the recursive process of writing; and 4) evaluating students' progress over time.

Moreover, classroom activities in an EAL academic writing course might include: analyzing sample articles from published sources and students' works, identifying the key components and their functions in the sample articles, and examining the language features of the articles. Other activities might include in-class and on-line discussions and reflections, group projects (e.g., survey report of a controversial or interesting topic), and demonstration of effective reading and writing strategies. Additionally, the instructor may introduce to the class such technologies as Blackboard class management, blogging, social media, overhead projector, PowerPoint presentation, E-mail and telephone interviews, and other Internet resources (e.g., web pages on academic writing). The class activities can be lectures, group work, pair work, and individual work.

In an academic writing class, the students may be asked to read authentic articles in real life and complete real communicative tasks. They analyze the sample articles in terms of the contexts of situation and develop effective strategies for specific writing tasks and contexts. The course may cover various topics in academic writing, such as: context of writing, reading and writing connections, process and product, computer technology and composition, close reading (to analyze context and rhetorical form) and speed reading (to retrieve information to be used in their writing), as well as collaborative and individual writing activities.

Though not necessarily having such a teaching philosophy in her mind, Raimes (1988) presented a method of teaching composition that illuminated the constructivists' teaching philosophy. Usually, composition teachers use a published book as textbook for a writing class and may use students' own work as a supplementary source. Raimes (1988) did the opposite. The primary texts (e.g., course book), as Raimes (1988) argued, should consist of the students' writing, teacher's feedback, and other authentic readings from real life (p. 46). In contrast, the published textbook should be taken as secondary text (source book) to offer some advice of writing, explanations of grammar, principles of editing, and readings for analysis (p. 45).

Furthermore, Raimes (1988) illustrated how she built a composition class around the three types of authentic primary texts with a teaching sequence that addressed common concerns in a writing class, e.g., purpose, audience, content, structure, and grammar (p. 46). The procedures went like this:

1) Students did free writing for 10 minutes to respond to a quote from an article about whether doctors should tell their patients the truth. 2) Students shared their written responses in groups of four with attention paid to the meaning not the grammar. 3) Each group reported their opinions to the whole class and the teacher wrote down the issues on the board. 4) Student read the whole article after school and responded to the main ideas in it with their double-entry notebook (with a summary of the reading on the right and responses, e.g., comments and questions, on the left). 5) Students wrote a first draft on the topic "Should doctors ever lie to benefit their patients?" 6) The next class was used for peer response. With a guided peer review sheet, students worked in pairs to review each other's essay. 7) The teacher provided feedback (comments and questions about content and organization) to each 
student's work for its strengths and weaknesses. 8) The teacher pointed out three areas of grammatical errors (e.g., verbs, agreement) for each student and had the students identify the sources of their errors, such as first language (L1) interference, overgeneralization of second language (L2) rules, and careless mistakes.

Perhaps some modifications can help enhance the effectiveness of this teaching sequence. First, topics of discussion can come from current online sources. Second, the teacher may demonstrate the process of composing (e.g., generating ideas, free writing, outlining) on the board or the big screen in front of the whole class. Third, the students can volunteer their own essay to be used by the teacher to demonstrate revising and editing in front of the class. Fourth, the writing prompt can be based on real life communicative tasks that involve problem-solving skills. For instance, your friend Tom needs to buy a gift for his advisor, a 40-year-old Asian male professor, please email Tom to offer three options as your suggestions and explain why.

\section{Conclusion}

From the point of view of constructivism, knowledge is constructed individually and collectively. This principle may be applicable to education in general, to the field of TESOL and to the EAL academic writing course, hence the EAL students need to construct their own knowledge in the academic writing class and pick up the collective knowledge in their academic community. Instructors need to mediate this learning process by responding to students' individual learning styles and needs, and responding to the specific learning contexts.

The instructors' teaching philosophy, methods, and styles are evolving. And the students' needs and teaching contexts are constantly changing. As such, teachers should adapt their teaching to students' learning needs and contexts. Therefore, contextualizing and individualizing the learning process with authentic texts through a diverse array of class activities may help EAL learners address their own needs and foster lifelong learning.

\section{References}

Caskurlu, S., Yukiko, M., Richardson, J. C., \& Lv, J. (2020). A meta analysis addressing the relationship between teaching presence and students' satisfaction and learning. Computers \& Education, 157, 1-16. https://doi.org/10.1016/j.compedu.2020.103966

Celce-Murcia, M. (2013). Language teaching approaches: An overview. In M. Celce-Murcia (Ed.), Teaching English as a second or foreign language (4th ed.). Boston: Heinle \& Heinle.

Ceylan, N. O. (2015). Fostering learner autonomy. Procedia-Social and Behavioral Sciences, 199, 85-93. https://doi.org/10.1016/j.sbspro.2015.07.491

Dimova, S. (2020). English language requirements for enrolment in EMI programs in higher education: A European case. Journal of English for Academic Purposes, 47, 1-13. https://doi.org/10.1016/j.jeap.2020.100896

Douglas, D. (2017). Review of the book Introducing needs analysis and English for specific purposes, by J.D. Brown. English for Specific Purposes, 48, 71-75. https://doi.org/10.1016/j.esp.2017.04.003

Eierman, R. J. (2008). The teaching philosophy statement: Purposes and organizational structure. Journal of Chemical Education, 85(3), 336-338. https://doi.org/10.1021/ed085p336

Ellis, R., Skehan, P., Li, S., Shintani, N., \& Lambert, C. (2019). Task-based language teaching: Theory and practice. UK: Cambridge University Press. https://doi.org/10.1017/9781108643689

Fu, Q. K., Lin, C. J., Hwang, G. J., \& Zhang, L. (2019). Impacts of a mind mapping-based contextual gaming approach on EFL students' writing performance, learning perceptions and generative uses in an English course. Computers \& Education, 137, 59-77. https://doi.org/10.1016/j.compedu.2019.04.005

Harmer, J. (2007). How to teach English. London: Pearson Longman. https://doi.org/10.1093/elt/ccn029

Howatt, A. P. R., \& Widdowson, H. G. (2004). A History of English Language Teaching (2nd ed.). Oxford: Oxford University Press.

Hyland, K. (2016). Methods and methodologies in second language writing research. System, 59, 116-125. https://doi.org/10.1016/j.system.2016.05.002

Matukhin, D., \& Bolgova, D. (2015). Learner-centered approach in Teaching Foreign Language: Psychological and pedagogical conditions. Procedia-Social and Behavioral Sciences, 206, 148-155. https://doi.org/10.1016/j.sbspro.2015.10.044

Mede, E., Dikilitaş, K., \& Atay, D. (2020). Pedagogic and instructional perspectives in language education: The context of higher education. New York: Peter Lang Publishing Group. https://doi.org/10.3726/b16464 
Merkel, W. (2020). "What I Mean Is...": The role of dialogic interactions in developing a statement of teaching philosophy. Journal of Second Language Writing, 48, 1-12. https://doi.org/10.1016/j.jslw.2019.100702

Palermo, C., \& Wilson, J. (2020). Implementing Automated Writing Evaluation in Different Instructional Contexts: A Mixed-Methods Study. Journal of Writing Research, 12(1), 63-108. https://doi.org/10.17239/jowr-2020.12.01.04

Piaget, J. (1970). Structuralism. New York: Basic Books.

Polio, C. (2017). Second language writing development: A research agenda. Language Teaching, 50(2), 261-275. https://doi.org/10.1017/S0261444817000015

Qvortrup, A., \& Wiberg, M. (Eds.). (2017). Dealing with conceptualisations of learning: Learning between means and aims in theory and practice. The Netherlands: Sense Publisher. https://doi.org/10.1007/978-94-6351-029-5

Raimes, A. (1988). The texts for teaching writing. In B. K. Das (Ed.), Materials for language learning and teaching (pp. 41-58). Singapore: SEAMEO Regional Language Center.

Savignon, S. (2006). Communicative Language Teaching. In K. Brown (Ed.), Encyclopedia of Language \& Linguistics (2nd ed., pp. 673-679). UK: Elsevier. https://doi.org/10.1016/B0-08-044854-2/00610-6

Vygotsky, L. S. (1981). The instrumental method in psychology. In J. V. Wertsch (Ed.), The concept of activity in Soviet psychology (pp. 134-143). Armonk, NY: M.E. Sharpe.

Wong, V. F., \& Lim, J. M. H. (2014). Linking communicative functions with linguistic resources in short stories: Implications of a narrative analysis for second language writing instruction. System, 45, 147-162. https://doi.org/10.1016/j.system.2014.05.008

Xiao, Y., Ma, Y., \& Chen, W. (2020). Review of the book Innovation in language learning and teaching: The case of China. In H. Reinders, D. Nunan \& B. Zou (Eds.), Australian Review of Applied Linguistics.

Xiao, Y., Zhao, A., \& Chen, W. (2020). Review of the book Intercultural perspectives on research writing. In P. Mur-Duenas \& J. Sinkuniene (Eds.), System.

Zhao, A., \& Xiao, Y. (2020). Review of the book English medium instruction programmes: Perspectives from South East Asian universities. In R. Barnard \& Z. Hasim (Eds.), Innovations in Education and Teaching International.

\section{Copyrights}

Copyright for this article is retained by the author, with first publication rights granted to the journal.

This is an open-access article distributed under the terms and conditions of the Creative Commons Attribution license (http://creativecommons.org/licenses/by/4.0/). 